\title{
Asymptomatic subjects with airway obstruction have significant impairment at exercise
}

\author{
Thibaud Soumagne, ${ }^{1,2}$ Pierantonio Laveneziana, ${ }^{3,4}$ Matthieu Veil-Picard, ${ }^{1,2}$ \\ Alicia Guillien ${ }^{1,5}$ Frédéric Claudé, ${ }^{1,2}$ Marc Puyraveau, ${ }^{6}$ Isabella Annesi-Maesano, ${ }^{7}$ \\ Nicolas Roche, ${ }^{8}$ Jean-Charles Dalphin, ${ }^{2,9}$ Bruno Degano ${ }^{1,5}$
}

\begin{abstract}
- Additional material is published online only. To view please visit the journal online (http://dx.doi.org/10.1136/ thoraxjn-2015-207953)

For numbered affiliations see end of article.
\end{abstract}

\section{Correspondence to} Professor Bruno Degano, CHU Jean Minjoz, 3 Boulevard Fleming, Besançon 25000, France;

bruno.degano@univ-fcomte.fr

Received 27 October 2015 Revised 12 April 2016 Accepted 28 April 2016 Published Online First 25 May 2016

\section{SLinked}

- http://dx.doi.org/10.1136/ thoraxinl-2016-208863

\section{CrossMark}

\section{To cite: Soumagne $T$,}

Laveneziana P, Veil-

Picard $\mathrm{M}$, et al. Thorax

2016;71:804-811.

\section{ABSTRACT}

Background The relevance of screening for airway obstruction in subjects not complaining of COPD symptoms may depend on the definition of airway obstruction. Response to exercise in asymptomatic subjects with persistent airway obstruction as defined by a postbronchodilator $\mathrm{FEV}_{1} / \mathrm{FVC}<5$ th centile lower limit of normal (LLN) remains unknown.

Methods Dyspnoea (Borg scale), exercise tolerance and ventilatory constraints on tidal volume expansion were assessed in 20 consecutive asymptomatic subjects with persistent mild airway obstruction detected by screening (postbronchodilator $\mathrm{FEV}_{1} / \mathrm{FVC}$ z-score: $-2.14 \pm 0.29$; $\mathrm{FEV}_{1}$ z-score: $\left.-1.02 \pm 0.64\right)$ undergoing incremental cycle cardiopulmonary exercise testing, compared with 20 healthy controls with normal spirometry matched for age, sex, body mass index and smoking history $\left(\mathrm{FEV}_{1} /\right.$ FVC z-score: $-0.13 \pm 0.57$; FEV 1 z-score: $0.32 \pm 0.67$ ) and with 20 symptomatic patients with COPD matched for the same characteristics (FEV $/$ /FVC z-score: -2.36 \pm 0.51 ; FEV 1 z-score: $-1.02 \pm 0.48$ ).

Results Asymptomatic subjects with airway obstruction had higher dyspnoea ratings than controls during incremental exercise. Asymptomatic subjects with airway obstruction had also peak oxygen consumption and peak power output that were lower than controls, and similar to those observed in patients with COPD.

Although less frequent than in COPD, dynamic hyperinflation was more frequent in asymptomatic subjects with airway obstruction than in controls $(85 \%$, $50 \%$ and $10 \%$, respectively; $p=0.01$ in asymptomatic subjects vs controls and $p=0.04$ vs (OPD).

Conclusions Although they did not present with chronic activity-related dyspnoea, subjects with a postbronchodilator $\mathrm{FEV}_{1} / \mathrm{FVC}<\mathrm{LLN}$ as detected by screening had poorer exercise tolerance than healthy controls on exertion, and a significant proportion of them had dynamic hyperinflation. These subjects may, therefore, deserve further attention and may warrant regular follow-up.

\section{INTRODUCTION}

The current definitions of COPD are based on the presence of some symptoms (cough, sputum and/or dyspnoea) together with persistent, irreversible airway obstruction. ${ }^{1}$ Population-based studies have shown that about half of COPD cases are of mild severity. ${ }^{2} 3$ Although they have normal $\mathrm{FEV}_{1}$ by definition, patients with mild COPD experience

\section{Key messages}

What is the key question?

- Do subjects without COPD symptoms but with persistent airway obstruction perform as well as normal subjects during exercise?

What is the bottom line?

- Although asymptomatic subjects with mild airway obstruction according to the GOLD (ie, $\mathrm{FEV}_{1} / \mathrm{FVC}$ ratio $<0.70$ ) do not differ from normal subjects at exercise, the physiological and perceptual responses to exercise in asymptomatic subjects with $\mathrm{FEV}_{1} / \mathrm{FVC}<$ lower limit of normal detected by screening remain unknown.

\section{Why read on?}

- This is the first study showing that subjects who do not complain of COPD symptoms but who have mild persistent airway obstruction as defined by a postbronchodilator $\mathrm{FEV}_{1} /$ $\mathrm{FVC}<$ lower limit of normal have poorer exercise tolerance and more frequent dynamic hyperinflation than healthy subjects with normal spirometry.

reduced exercise tolerance and greater exertional dyspnoea ratings at a given work rate (WR) compared with healthy controls. ${ }^{4}$ Ventilatory abnormalities during exercise include significant dynamic lung hyperinflation and early mechanical constraints on tidal volume (VT) expansion. ${ }^{4}{ }^{6}$ This has led to the conclusion that patients with mild COPD should be identified and might be eligible for treatment with bronchodilators. ${ }^{7}$

In at-risk subjects who complain of symptoms, early detection of COPD has been proven to be effective and is now recommended. ${ }^{18}$ Nevertheless, this strategy is unable to detect COPD in subjects who do not report any symptom. ${ }^{39}$ COPD screening programmes in asymptomatic at-risk individuals have, therefore, been evaluated. ${ }^{10}{ }^{11}$ Identifying airway obstruction, as defined by an $\mathrm{FEV}_{1} / \mathrm{FVC}$ ratio below the fixed cut-off of 0.70 in asymptomatic subjects, does not appear to be beneficial because they do not have an accelerated decline in $\mathrm{FEV}_{1}$ and are not at higher risk of premature 
death. ${ }^{12-14}$ In contrast, even in the absence of COPD-related symptoms, subjects with persistent airway obstruction defined by a postbronchodilator $\mathrm{FEV}_{1} / \mathrm{FVC}$ ratio below the statistically based, age-specific lower limit of normal (LLN) are at risk of premature death and/or of development of respiratory symptoms, ${ }^{15}{ }^{16}$ suggesting that their identification is pertinent.

Díaz et al showed that asymptomatic subjects with an $\mathrm{FEV}_{1} /$ FVC ratio $<0.70$ had similar exercise tolerance to healthy subjects. ${ }^{6}$ Of note, contrary to the LLN cut-off, the fixed cut-off of 0.70 for $\mathrm{FEV}_{1} / \mathrm{FVC}$ may inappropriately lead to a diagnosis of airway obstruction in subjects older than 50 years. ${ }^{17}$ To date, exercise tolerance and dynamic ventilatory mechanics during exercise in asymptomatic subjects with persistent airway obstruction defined as $\mathrm{FEV}_{1} / \mathrm{FVC}<\mathrm{LLN}$ remain undetermined. The aim of the current study was, therefore, to measure dyspnoea intensity during exertion, exercise tolerance and ventilatory mechanics in a group of subjects with a history of smoking who did not present with symptoms of COPD and in whom mild persistent airway obstruction, defined as postbronchodilator $\mathrm{FEV}_{1} / \mathrm{FVC}<\mathrm{LLN}$, along with normal $\mathrm{FEV}_{1}$, was detected by screening. In order to determine whether asymptomatic subjects with airway obstruction behave like healthy subjects or like subjects with COPD during exercise, measurements in asymptomatic subjects with airway obstruction were compared with those of a group of healthy controls with normal spirometry matched for age, sex and smoking status, and with those of a group of symptomatic patients with COPD matched for age, sex, postbronchodilator spirometry and smoking status.

\section{METHODS}

\section{Study design}

Asymptomatic subjects with airway obstruction and healthy controls were recruited between September 2012 and December 2013 through a regional COPD screening programme involving general practitioners. ${ }^{18}$ General practitioners were asked to propose spirometry to all patients aged $40-75$ years who were considered at risk for COPD. A bronchodilation test was applied by administering four separate puffs of $100 \mu \mathrm{g}$ each of salbutamol through a spacer device, as described elsewhere. ${ }^{19}$ During this period, 2374 subjects participated in the screening programme; the 20 first asymptomatic subjects detected with persistent airway obstruction who met the inclusion criteria of the current study and who accepted to participate were included. Twenty healthy subjects participating in the screening programme were frequency matched with the asymptomatic subjects with airway obstruction in terms of age, body mass index (BMI), tobacco smoking (in pack-years) and sex. Finally, 20 patients with COPD were selected among those who were referred to our department by their general practitioner or by a pulmonologist; these patients were also frequency matched with asymptomatic subjects with airway obstruction for postbronchodilator $\mathrm{FEV}_{1}$, postbronchodilator $\mathrm{FEV}_{1} / \mathrm{FVC}$, age, BMI, tobacco smoking (in pack-years) and sex. Ethics committee approval was received from the local Ethics Committee (CPP Est; P-2011-119), and written consent was obtained from all subjects.

\section{Subjects}

Persistent airway obstruction was defined as a postbronchodilator $\mathrm{FEV}_{1} / \mathrm{FVC}$ ratio $<5$ th centile $\mathrm{LLN}$, according to the GLI-2012 equation. ${ }^{20}$ Inclusion criteria for the asymptomatic group with airway obstruction were: cumulative tobacco smoking history $>15$ pack-years, a normal $\mathrm{FEV}_{1}$ (z-score $>-1.64$ ), a modified Medical Research Council (mMRC) score equal to zero and the absence of chronic cough and/or chronic expectoration.

Inclusion criteria for healthy subjects were: normal baseline spirometry $\left(\mathrm{FEV}_{1}>\mathrm{LLN}, \mathrm{FEV}_{1} / \mathrm{FVC}>\mathrm{LLN}\right)$, an mMRC score equal to zero and the absence of any respiratory symptoms.

The exclusion criteria for all subjects including patients with COPD were (i) a history of any medical conditions that could cause or contribute to breathlessness (ie, respiratory disease (including asthma, either self-reported or confirmed by a doctor) other than COPD (if appropriate) and/or cardiovascular disease) and/or (ii) other disorders that could interfere with exercise testing. ${ }^{4}$

\section{Data collection}

Subjects attended a single visit. If required, COPD subjects were asked to interrupt any respiratory medication such as short and long-acting bronchodilators $72 \mathrm{~h}$ prior to the visit. Subjects were asked to arrive early in the morning. They then underwent pulmonary function testing prebronchodilator and $30 \mathrm{~min}$ postbronchodilator administration (nebulisation of terbutaline $(5 \mathrm{mg} / 2 \mathrm{~mL})$ and ipratropium bromide $(0.5 \mathrm{mg} / 2 \mathrm{~mL})$ for $15 \mathrm{~min})$. A symptom-limited incremental cycle ergometer cardiopulmonary exercise testing (CPET) was performed on the same day, at least $6 \mathrm{~h}$ after the bronchodilator test and at least $4 \mathrm{~h}$ after the meal.

\section{Procedures}

Routine spirometry, constant-volume body plethysmography and single breath lung transfer for carbon monoxide (TLCO) were performed in accordance with recommended techniques (Platinum Elite; MGC Diagnostics Corporation, Saint Paul, Minnesota, USA). ${ }^{21} 22$

Symptom-limited incremental CPET was performed on an electronically braked cycle ergometer (Ergometrics 900; Ergoline; Bitz, Germany). After a steady-state resting period, a 3 min warm-up was conducted at about $20 \%$ of individually estimated maximal work load, and the load was increased every minute such that the CPET duration was between 8 and 12 min. $^{23}$ Tests were terminated at the point of symptom limitation (peak exercise). Physiological data were obtained breath by breath (MGC-CPX System; MGC Diagnostics Corporation) and were expressed as $30 \mathrm{~s}$ averages, according to recommended guidelines. $^{23}$ Exercise variables were compared with predicted values. $^{24}$ Blood samples were drawn from the arterialised earlobe.

Subjects rated the magnitude of their perceived breathing and leg discomfort by pointing to a number on the 10-point Borg scale. ${ }^{25}$ Changes in end-expiratory lung volume were estimated from inspiratory capacity (IC) measurements at rest, at the end of each $1 \mathrm{~min}$ increment of exercise and at peak exercise. Dynamic hyperinflation was defined as a decrease of $>150 \mathrm{~mL}$ in IC compared with resting levels at any time point during exercise. $^{26}$

Ventilatory equivalent for carbon dioxide $\left(\mathrm{V}^{\prime} \mathrm{E} / \mathrm{V}^{\prime} \mathrm{CO}_{2}\right.$ ratio) plotted against WR and its nadir were used as surrogate markers of ventilatory efficiency.

In the relationship between VT and minute ventilation $\left(\mathrm{V}^{\prime} \mathrm{E}\right)$, there is an inflection point beyond which almost no further change in VT occurs despite a continued increase in $\mathrm{V}^{\prime} \mathrm{E}{ }^{27}$ This inflection in the VT response marks the point where dyspnoea sharply increases because of mechanical constraints on VT expansion. $^{27}$ This inflection point was determined by two trained observers (BD and TS) for each patient by analysing individual plots of $\mathrm{V}^{\prime} \mathrm{E}$ versus $\mathrm{VT}^{28}$ 


\section{Statistical analysis}

A sample size of 20 subjects in each group was estimated to provide $80 \%$ power to detect a significant difference between asymptomatic subjects with airway obstruction and healthy controls in dyspnoea intensity (Borg scale) measured at a standardised WR during incremental cycle exercise based on a relevant difference in Borg ratings of \pm 1 , an $S D=1$ unit, $\alpha=0.05$ and a two-tailed test of significance. ${ }^{29}$

Between-group comparisons of subjects' characteristics were performed using unpaired t tests. Comparisons of categorical data between groups were performed using Fisher's exact test. Repeated measures analysis of variance (ANOVA) was performed to evaluate differences between the three groups for measurements made at different time points and/or intensities during exercise. Scheffe's tests were applied to evaluate pairwise comparisons when a significant difference was found by ANOVA.

All reported $\mathrm{p}$ values were two-sided, with a significance level set at $\mathrm{p}<0.05$. Statistical analysis was performed using SAS V.9.3 (SAS Institute, Cary, North Carolina, USA).

\section{RESULTS}

\section{Subject characteristics}

By design, all three groups had similar sex distribution, age, tobacco smoking and BMI (table 1), and none of the included subjects or patients had a history of angina, myocardial infarction or heart failure. Comorbidities in the three groups were well controlled: systemic hypertension $(n=3 ; n=4 ; n=5$, in asymptomatic subjects with airway obstruction, patients with COPD and healthy controls, respectively), diabetes mellitus type $2(n=1 ; n=1 ; n=0$, respectively), hypercholesterolaemia $(n=4 ; n=6 ; n=3$, respectively), gastro-oesophageal reflux disease $(n=1 ; n=3 ; n=0$, respectively) and obstructive sleep apnoea $(n=1 ; n=0 ; n=0$, respectively). Among the 60 studied subjects, only six patients with COPD were taking long-term bronchodilators at the time of screening, and none were taking inhaled corticosteroids.

\section{Pulmonary function and health status}

Pulmonary function of asymptomatic subjects with airway obstruction was significantly different than that of healthy controls, and was close to that of patients with COPD (table 1 and see online supplementary table S1). Subjects from all groups

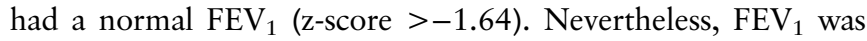
significantly lower in the two groups with airway obstruction than in normal subjects. Small airways dysfunction, judged by a reduction in maximal midexpiratory flows (FEF25-75), was absent in healthy controls, and was significant (mean z-score $<-1.64$ ) in the two groups with airway obstruction.

Asymptomatic subjects with airway obstruction and healthy subjects had similar health status (St George's Respiratory

Table 1 Characteristics, respiratory symptoms and pulmonary function in subjects with mild asymptomatic airway obstruction, patients with mild COPD and healthy controls

\begin{tabular}{|c|c|c|c|}
\hline & $\begin{array}{l}\text { Asymptomatic airway obstruction } \\
(n=20)\end{array}$ & $\begin{array}{l}\text { COPD } \\
(n=20)\end{array}$ & $\begin{array}{l}\text { Healthy controls } \\
(n=20)\end{array}$ \\
\hline \multicolumn{4}{|l|}{ Demographics } \\
\hline Male, \% & 85 & 85 & 85 \\
\hline Age, year & $60.4 \pm 8.3$ & $60.3 \pm 9.3$ & $60.7 \pm 6.4$ \\
\hline Body mass index, $\mathrm{kg} / \mathrm{m}^{2}$ & $26.5 \pm 3.1$ & $26.8 \pm 4.2$ & $26.6 \pm 3.7$ \\
\hline Tobacco, pack-years & $19.3 \pm 16.9$ & $19.4 \pm 14.8$ & $17.7 \pm 18.4$ \\
\hline Current smokers, \% & 55 & 50 & 55 \\
\hline \multicolumn{4}{|l|}{ Symptoms } \\
\hline Chronic cough, n (\%) & $0^{*}$ & $13(65)^{\sharp}$ & 0 \\
\hline Chronic sputum, n (\%) & $0^{*}$ & $9(45)^{\#}$ & 0 \\
\hline mMRC dyspnoea scale (0-4) & $0^{*}$ & $1.25 \pm 0.55^{\sharp}$ & 0 \\
\hline BDI dyspnoea scale (0-12) & $11.5 \pm 0.7^{*}$ & $9.5 \pm 1.3^{\sharp}$ & $11.7 \pm 0.7$ \\
\hline SGRQ & $8.7 \pm 0.7^{*}$ & $19.0 \pm 0.6^{\sharp}$ & $6.8 \pm 0.8$ \\
\hline CAT score $(0-40)$ & $7.6 \pm 3.4$ & $10.9 \pm 6.5$ & - \\
\hline \multicolumn{4}{|l|}{ Pulmonary function tests } \\
\hline Post-BD FEV 1 , L (z-score) & $2.81 \pm 0.58^{\sharp}(-1.02 \pm 0.64)^{\sharp}$ & $2.82 \pm 0.57^{\sharp}(-1.02 \pm 0.48)^{\sharp}$ & $3.40 \pm 0.62(0.32 \pm 0.67)$ \\
\hline Post-BD FEV $/$ FVC, \% (z-score) & $61.4 \pm 4.1^{\sharp}(-2.14 \pm 0.29)^{\sharp}$ & $59.3 \pm 4.9^{\sharp}(-2.36 \pm 0.51)^{\sharp}$ & $76.9 \pm 4.0(-0.13 \pm 0.57)$ \\
\hline \multicolumn{4}{|l|}{ Pre-BD pulmonary function } \\
\hline $\mathrm{FEV}_{1}, \mathrm{~L}$ (z-score) & $2.67 \pm 0.52^{\sharp}(-1.10 \pm 0.50)^{\sharp}$ & $2.64 \pm 0.59^{\sharp}(-1.13 \pm 0.49)^{\sharp}$ & $3.29 \pm 0.63(0.27 \pm 0.69)$ \\
\hline FVC, L (z-score) & $4.43 \pm 0.83(0.28 \pm 0.87)$ & $4.55 \pm 1.01(0.32 \pm 1.03)$ & $4.48 \pm 0.85(0.45 \pm 0.73)$ \\
\hline FRC, L (z-score) & $3.73 \pm 0.58(0.54 \pm 0.91)$ & $4.10 \pm 0.94(1.22 \pm 1.45)$ & $3.72 \pm 0.81(0.57 \pm 1.23)$ \\
\hline IC, L & $3.19 \pm 0.59$ & $3.12 \pm 0.63$ & $3.37 \pm 0.71$ \\
\hline FEF25-75, \% (z-score) & $1.22 \pm 0.37^{\sharp}(-2.17 \pm 0.25)^{\sharp}$ & $1.17 \pm 0.35^{\sharp}(-2.35 \pm 0.48)^{\sharp}$ & $2.52 \pm 0.73(-0.87 \pm 0.51)$ \\
\hline RV, L (z-score) & $2.33 \pm 0.51 *(0.04 \pm 1.20)^{*}$ & $2.88 \pm 0.72(1.34 \pm 1.81)^{\sharp}$ & $2.34 \pm 0.61(0.22 \pm 1.47)$ \\
\hline TLC, L (z-score) & $6.92 \pm 0.81(0.46 \pm 0.80)$ & $7.22 \pm 0.82(0.89 \pm 0.91)$ & $7.09 \pm 1.24(0.95 \pm 1.28)$ \\
\hline RV/TLC, \% & $33.7 \pm 7.3(-0.81 \pm 1.05)$ & $39.9 \pm 8.7^{\sharp}(0.44 \pm 1.55)$ & $33.0 \pm 6.5(-0.75 \pm 0.90)$ \\
\hline VA/TLC, \% & $89.7 \pm 7.6$ & $87.6 \pm 10.1$ & $87.5 \pm 5.6$ \\
\hline TLCO, mmol/min/kPa (z-score) & $7.47 \pm 1.84^{\sharp}(-1.27 \pm 1.07)^{\sharp}$ & $7.60 \pm 2.41^{\sharp}(-1.21 \pm 1.46)^{\sharp}$ & $8.67 \pm 1.47(-0.22 \pm 1.08)$ \\
\hline $\mathrm{KCO}, \mathrm{mmol} / \mathrm{min} / \mathrm{kPa} / \mathrm{L}$ (z-score) & $1.20 \pm 0.21^{\sharp}(-0.53 \pm 0.66)^{\sharp}$ & $1.20 \pm 0.32^{\sharp}(-0.51 \pm 1.06)^{\sharp}$ & $1.40 \pm 0.19(0.12 \pm 0.63)$ \\
\hline
\end{tabular}


Table 2 Measurements at peak symptom-limited incremental cycle exercise

\begin{tabular}{|c|c|c|c|}
\hline & $\begin{array}{l}\text { Asymptomatic airway obstruction } \\
(\mathrm{n}=20)\end{array}$ & $\begin{array}{l}\text { COPD } \\
(n=20)\end{array}$ & $\begin{array}{l}\text { Healthy controls } \\
(n=20)\end{array}$ \\
\hline Dyspnoea, Borg scale & $8.3 \pm 1.9$ & $9.1 \pm 1.3$ & $7.6 \pm 2.2$ \\
\hline Leg discomfort, Borg scale & $8.1 \pm 1.8$ & $9.2 \pm 1.4$ & $7.8 \pm 1.6$ \\
\hline \multicolumn{4}{|l|}{ Reason for stopping } \\
\hline Breathing discomfort & $6(30 \%)$ & $2(10 \%)$ & 0 \\
\hline Leg discomfort & $3(15 \%)$ & $7(35 \%)$ & $1(5 \%)$ \\
\hline Both breathing and leg discomfort & $11(55 \%)$ & $11(55 \%)$ & $19(95 \%)$ \\
\hline Work rate, W (\% predicted) & $152 \pm 44^{\sharp}(109 \pm 22)^{\sharp}$ & $151 \pm 42^{\sharp}(104 \pm 12)^{\sharp}$ & $184 \pm 43(128 \pm 21)$ \\
\hline $\mathrm{V}^{\prime} \mathrm{O}_{2}, \mathrm{~L} / \mathrm{min}$ (\% predicted) & $1.95 \pm 0.50^{\sharp}(90 \pm 18)^{\sharp}$ & $1.91 \pm 0.62^{\sharp}(90 \pm 23)^{\sharp}$ & $2.25 \pm 0.49^{\sharp}(106 \pm 19)$ \\
\hline RER & $1.16 \pm 0.07$ & $1.13 \pm 0.05$ & $1.16 \pm 0.06$ \\
\hline $\mathrm{HR}, \%$ predicted maximum & $98.3 \pm 8.0$ & $96.9 \pm 9.1$ & $101.4 \pm 7.1$ \\
\hline $\mathrm{O}_{2}$ pulse, $\mathrm{mL} \mathrm{O}_{2} /$ beat & $12.6 \pm 2.8$ & $12.8 \pm 3.8$ & $13.6 \pm 3.2$ \\
\hline $\mathrm{PcapO}_{2}, \mathrm{kPa}$ & $11.32 \pm 0.84$ & $10.84 \pm 1.52^{\#}$ & $11.84 \pm 0.72$ \\
\hline $\mathrm{PcapCO}_{2}, \mathrm{kPa}$ & $4.49 \pm 0.51$ & $4.88 \pm 0,59$ & $4.65 \pm 0.33$ \\
\hline $\mathrm{V}^{\prime} \mathrm{E}, \mathrm{L} / \mathrm{min}$ (\% estimated MVV) & $77.1 \pm 19.7(74.8 \pm 15.3)$ & $73.8 \pm 18.0(75.0 \pm 12.6)$ & $81.1 \pm 17.4(68.2 \pm 15.3)$ \\
\hline $\mathrm{f}$, breaths/min & $32.2 \pm 7.9$ & $33.7 \pm 6.9$ & $31.0 \pm 6.4$ \\
\hline VT, L & $2.40 \pm 0.54$ & $2.19 \pm 0.67^{\sharp}$ & $2.62 \pm 0.51$ \\
\hline IC, L & $3.10 \pm 0.62^{*, \#}$ & $2.72 \pm 0.68^{\sharp}$ & $3.55 \pm 0.78$ \\
\hline IRV, L & $0.70 \pm 0.41$ & $0.53 \pm 0.39^{\sharp}$ & $0.93 \pm 0.51$ \\
\hline $\mathrm{V}^{\prime} \mathrm{E} / \mathrm{N}^{\prime} \mathrm{O}_{2}$ & $41.8 \pm 7.9$ & $42.1 \pm 12.1$ & $38.8 \pm 6.0$ \\
\hline $\mathrm{V}^{\prime} \mathrm{E} / \mathrm{V}^{\prime} \mathrm{CO}_{2}$ & $36.0 \pm 4.7$ & $37.1 \pm 10.4$ & $33.4 \pm 4.1$ \\
\hline
\end{tabular}

Questionnaire (SGRQ)) and baseline dyspnoea index (BDI); however, SGQR and BDI were poorer in COPD subjects compared with the two other groups (table 1). All patients in the COPD group presented with chronic activity-related dyspnoea $(\mathrm{mMRC} \geq 1)$, and a majority of them also reported chronic cough and/or chronic sputum production (table 1).

Poorly communicating fraction of total lung capacity (TLC), as assessed by the ratio of alveolar volume to TLC, was similar in the three groups (table 1).

\section{Symptom-limited incremental cycle exercise}

All subjects and patients performed a maximal exercise (respiratory exchange ratio $>1.1$ ). Asymptomatic subjects with airway obstruction had lower peak WR and lower peak oxygen consumption $\left(\mathrm{V}^{\prime} \mathrm{O}_{2}\right)$ than healthy controls (table 2$)$.

Dyspnoea/WR slope was significantly higher in asymptomatic subjects with airway obstruction than in healthy controls (ANOVA repeated measures). Borg scale rating was higher by more than 1 unit in asymptomatic subjects with airway obstruction than in healthy controls at 60 and at $80 \mathrm{~W}$ (figure 1 and table 3). Similarly, Borg scale ratings as a function of $\mathrm{V}^{\prime} \mathrm{E}$ were higher in asymptomatic subjects with airway obstruction than in healthy controls (figure 1 and table 4).

Although the COPD group had the greatest reduction in IC during exercise, the group of asymptomatic subjects with airway obstruction also had a greater reduction in IC during exercise than healthy controls (figure 2 and see online supplementary figure S1). Significant dynamic hyperinflation was found in 10 asymptomatic subjects with airway obstruction (50\%), two healthy controls (10\%) and 17 patients with COPD (85\%; $\mathrm{p}<0.01$ in asymptomatic subjects vs controls and vs COPD).

The VT/V'E inflection point occurred at similar $\mathrm{V}^{\prime} \mathrm{E}$ and VT in the group of asymptomatic subjects with airway obstruction and in the control group, and at significantly lower VT and $\mathrm{V}^{\prime} \mathrm{E}$ in the COPD group compared with the two other groups (figure 3).
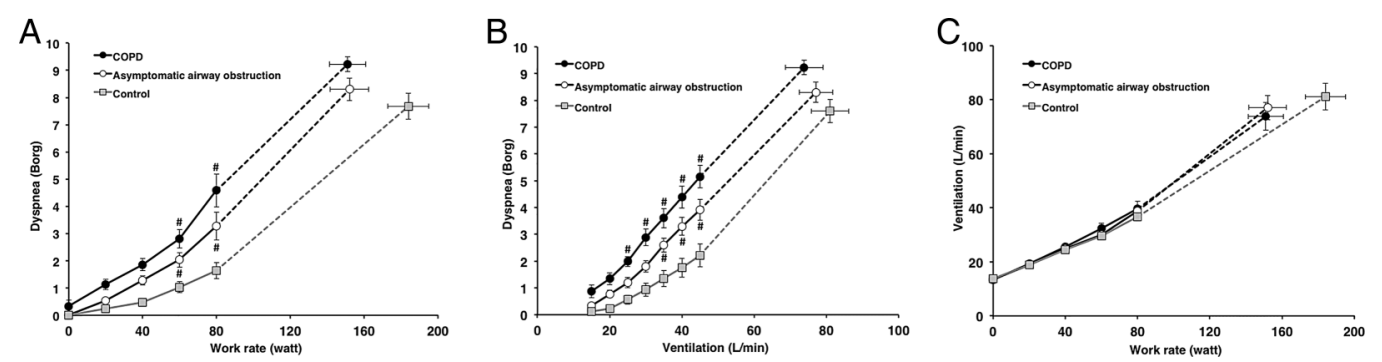

Figure 1 Exertional dyspnoea intensity during incremental cycle exercise testing in asymptomatic subjects with airway obstruction, healthy control subjects matched for age, body mass index, smoking status and sex; and matched patients with COPD is shown relative to work rate (A) and minute ventilation (B). Dyspnoea to work rate and dyspnoea to minute ventilation slopes were significantly different between asymptomatic subjects with airway obstruction and healthy controls (analysis of variance repeated measures). These slopes were, however, not significantly different between asymptomatic subjects with airway obstruction and patients with COPD. Of note, the relationship between work rate and minute ventilation was superimposed in the three groups (C). Values are means \pm SEM. ${ }^{\sharp} p<0.05$ versus healthy controls at a standardised work rate (Scheffe's tests). 
Table 3 Measurements at highest common work rate $(80 \mathrm{~W})$ in subjects with mild asymptomatic airway obstruction, patients with mild COPD and healthy controls

\begin{tabular}{|c|c|c|c|}
\hline & $\begin{array}{l}\text { Asymptomatic } \\
\text { airway obstruction } \\
(n=20)\end{array}$ & $\begin{array}{l}\text { COPD } \\
(n=20)\end{array}$ & $\begin{array}{l}\text { Healthy } \\
\text { controls } \\
(n=20)\end{array}$ \\
\hline Dyspnoea, Borg scale & $3.3 \pm 2.1^{\#}$ & $4.6 \pm 2.7^{\sharp}$ & $1.6 \pm 1.3$ \\
\hline Leg discomfort, Borg scale & $3.7 \pm 3.0$ & $5.1 \pm 2.7$ & $3.0 \pm 3.0$ \\
\hline $\mathrm{V}^{\prime} \mathrm{O}_{2}, \mathrm{~L} / \mathrm{min}$ & $1.19 \pm 0.18$ & $1.20 \pm 0.20$ & $1.27 \pm 0.17$ \\
\hline $\mathrm{HR}, \%$ predicted maximum & $73.3 \pm 8.0$ & $73.0 \pm 9.1$ & $71.2 \pm 7.1$ \\
\hline $\mathrm{O}_{2}$ pulse, $\mathrm{mL} \mathrm{O} /$ beat & $10.2 \pm 2.8$ & $10.3 \pm 3.6$ & $11.2 \pm 3.4$ \\
\hline$V^{\prime} E_{1}, L / m i n$ & $38.8 \pm 6.9$ & $39.7 \pm 11.9$ & $36.7 \pm 6.9$ \\
\hline f, breaths/min & $21.6 \pm 6.1$ & $23.1 \pm 9.1$ & $19.7 \pm 4.0$ \\
\hline VT, L & $1.80 \pm 0.29$ & $1.72 \pm 0.46$ & $1.86 \pm 0.38$ \\
\hline IRV, L & $1.42 \pm 0.63$ & $1.29 \pm 0.56^{\sharp}$ & $1.78 \pm 0.69$ \\
\hline IC, L & $3.22 \pm 0.61^{\sharp}$ & $3.01 \pm 0.76^{\sharp}$ & $3.64 \pm 0.74$ \\
\hline
\end{tabular}

Values are means \pm SD. ${ }^{\#} p<0.05$ versus controls.

$\mathrm{f}$, respiratory rate; $H R$, heart rate; IC, inspiratory capacity; IRV, inspiratory reserve volume; $V^{\prime} \mathrm{O}_{2}$, oxygen uptake; $V^{\prime} \mathrm{E}$, minute ventilation; $\mathrm{V}^{\prime} E / \mathrm{V}^{\prime} \mathrm{CO}_{2}$, ventilatory equivalents for carbon dioxide; VT, tidal volume.

Nadir $\mathrm{V}^{\prime} \mathrm{E} / \mathrm{V}^{\prime} \mathrm{CO}_{2}$ was modestly but significantly higher in asymptomatic subjects with airway obstruction than in healthy controls $(31.5 \pm 3.4$ and $29.2 \pm 3.1$, respectively; $\mathrm{p}<0.05)$, but was similar in the two groups with airway obstruction $(33.1$ \pm 7.4 in patients with COPD; $p<0.05$ in COPD vs healthy controls; non significant in COPD vs asymptomatic subjects with airway obstruction).

Among the functional parameter measured at rest, the best correlates of IC (expressed as \% baseline) measured at the highest common WR $(80 \mathrm{~W})$ were $\mathrm{FEV}_{1} / \mathrm{FVC} \quad(\mathrm{r}=0.49$, $\mathrm{p}<0.01)$, TLCO $(\mathrm{r}=0.35, \mathrm{p}<0.05)$ and $\mathrm{FEV}_{1} \quad(\mathrm{p}=0.34$, $\mathrm{p}<0.05$ ). The best physiological correlate of dyspnoea intensity at this highest common WR was the concurrent IC expressed as $\%$ baseline $(\mathrm{r}=-0.61 ; \mathrm{p}<0.001)$. There was a weaker but significant correlation between dyspnoea ratings and inspiratory reserve volume (IRV) $(\mathrm{r}=-0.35, \mathrm{p}=0.02)$ at this WR.

\section{DISCUSSION}

The main findings of this study are as follows: (i) subjects with mild airway obstruction, defined as postbronchodilator

Table 4 Measurements at highest common ventilation rate (45 L/min) in subjects with mild asymptomatic airway obstruction, patients with mild COPD and healthy controls

\begin{tabular}{|c|c|c|c|}
\hline & $\begin{array}{l}\text { Asymptomatic } \\
\text { airway obstruction } \\
(n=20)\end{array}$ & $\begin{array}{l}\text { COPD } \\
(n=20)\end{array}$ & $\begin{array}{l}\text { Healthy } \\
\text { controls } \\
(n=20)\end{array}$ \\
\hline Dyspnoea, Borg scale & $3.8 \pm 1.9^{\sharp}$ & $5.1 \pm 2.5^{\sharp}$ & $2.2 \pm 1.8$ \\
\hline Leg discomfort, Borg scale & $4.2 \pm 2.2$ & $4.8 \pm 1.7^{\sharp}$ & $2.8 \pm 1.8$ \\
\hline Work rate, W & $100 \pm 28$ & $98 \pm 37$ & $103 \pm 39$ \\
\hline $\mathrm{V}^{\prime} \mathrm{O}_{2}, \mathrm{~L} / \mathrm{min}$ & $1.41 \pm 0.35$ & $1.40 \pm 0.45$ & $1.48 \pm 0.41$ \\
\hline $\mathrm{HR}, \%$ predicted maximum & $78.3 \pm 8.7$ & $79.8 \pm 9.1$ & $76.7 \pm 7.1$ \\
\hline $\mathrm{O}_{2}$ pulse, $\mathrm{mL} \mathrm{O}_{2} /$ beat & $11.2 \pm 2.8$ & $10.9 \pm 3.6$ & $12.0 \pm 3.0$ \\
\hline $\mathrm{f}$, breaths/min & $21.0 \pm 4.8$ & $24.4 \pm 7.2^{\sharp}$ & $20.8 \pm 3.6$ \\
\hline IRV, L & $1.10 \pm 0.57$ & $1.15 \pm 0.54$ & $1.48 \pm 0.60$ \\
\hline IC, L & $3.15 \pm 0.62$ & $3.00 \pm 0.74^{\#}$ & $3.64 \pm 0.71$ \\
\hline VT, L & $2.14 \pm 0.44^{*}$ & $1.84 \pm 0.52^{\sharp}$ & $2.16 \pm 0.39$ \\
\hline
\end{tabular}

Values are means \pm SD. ${ }^{*} p<0.05$ versus COPD; ${ }^{\sharp} p<0.05$ versus controls.

$\mathrm{f}$, respiratory rate; $\mathrm{HR}$, heart rate; IC, inspiratory capacity; IRV, inspiratory reserve volume; $\mathrm{V}^{\prime} \mathrm{O}_{2}$, oxygen uptake; VT, tidal volume.
$\mathrm{FEV}_{1} / \mathrm{FVC}<\mathrm{LLN}$ together with normal $\mathrm{FEV}_{1}$, who do not present with any COPD symptom had, however, greater dyspnoea intensity during incremental exercise and poorer peak exercise capacity than matched healthy subjects with normal spirometry; (ii) these asymptomatic subjects with airway obstruction had a greater reduction in IC than healthy controls during exercise, and half of them had significant dynamic lung hyperinflation on exertion.

Asymptomatic subjects with mild airway obstruction are likely to be regularly identified because case-finding or population screening for COPD are being considered worldwide. ${ }^{30}$ The last Global Initiative for Chronic Obstructive Lung Disease statement acknowledges that significant airway obstruction may develop without any history of the main COPD symptoms. ${ }^{1}$ Therefore, screening programmes make it possible to diagnose persistent airway obstruction in subjects who do not present with dyspnoea, chronic cough and/or chronic sputum production. ${ }^{30-33}$ Recently, the analysis of a large sample of adults aged $\geq 40$ years who participated in screening programmes worldwide indicated that more than $80 \%$ of subjects found to have airway obstruction defined as postbronchodilator $\mathrm{FEV}_{1} / \mathrm{FVC}<\mathrm{LLN}$ were previously undiagnosed, and that the absence of complaints of COPD symptoms (dyspnoea, chronic cough and/or chronic sputum production) was associated with undiagnosed airway obstruction. ${ }^{30}$

Díaz et al reported that asymptomatic subjects with persistent airway obstruction as defined by an $\mathrm{FEV}_{1} / \mathrm{FVC}$ below the fixed ratio of 0.70 had exercise tolerance similar to that of healthy subjects. ${ }^{6}$ This conclusion was drawn from the analysis of a group of 22 subjects who did not present with symptoms of COPD, with a mean age of 61 years and a mean $\mathrm{FEV}_{1} / \mathrm{FVC}$ ratio of $68 \% .^{6}$ As the $\mathrm{FEV}_{1} / \mathrm{FVC}$ ratio normally declines with age in healthy non-smokers, ${ }^{17}$ it is plausible that for most subjects in the study by Díaz et al, the fixed cut-off of 0.70 did not represent the $\mathrm{LLN}$ for $\mathrm{FEV}_{1} / \mathrm{FVC}$. In other words, we cannot exclude the possibility that most 'asymptomatic' subjects in the study by Díaz et al did not, in fact, have significant airway obstruction.

By contrast, we found in our study that mild airway obstruction as defined by an $\mathrm{FEV}_{1} / \mathrm{FVC}$ ratio below the LLN had an impact on maximal exercise capacity and on ventilatory behaviour in subjects who did not report activity-related dyspnoea. Of note, our two matched groups with airway obstruction (either asymptomatic or COPD) had a similar decrease of peak exercise capacity and peak $\mathrm{V}^{\prime} \mathrm{O}_{2}$ by comparison with healthy controls, and a significant proportion of subjects developed dynamic hyperinflation in these two groups. Borg dyspnoea ratings during exercise were not identical in these two groups with airway obstruction, but both groups had significantly higher dyspnoea/WR slopes than healthy controls. The significant correlation between Borg dyspnoea rating and IC at the highest common WR suggests that differences in dynamic hyperinflation explain at least in part differences in dyspnoea. Nevertheless, the reasons why with similar resting airway obstruction some subjects present with activity-related dyspnoea while other do not is intriguing. As TLCO and carbon monoxide transfer coefficient were similar in our two groups with very similar airway obstruction, it is likely that the extent of lung parenchymal destruction was also similar. ${ }^{34} \mathrm{~V}^{\prime} \mathrm{E}$ as a function of WR was strictly similar in all groups throughout exercise: it is, therefore, very unlikely that differences in dyspnoea were secondary to differences in ventilatory demand. The fact that the inflection point in the VT expansion occurred at a lower $\mathrm{V}^{\prime} \mathrm{E}$ and at a lower VT in the COPD group than in the group of subjects with 

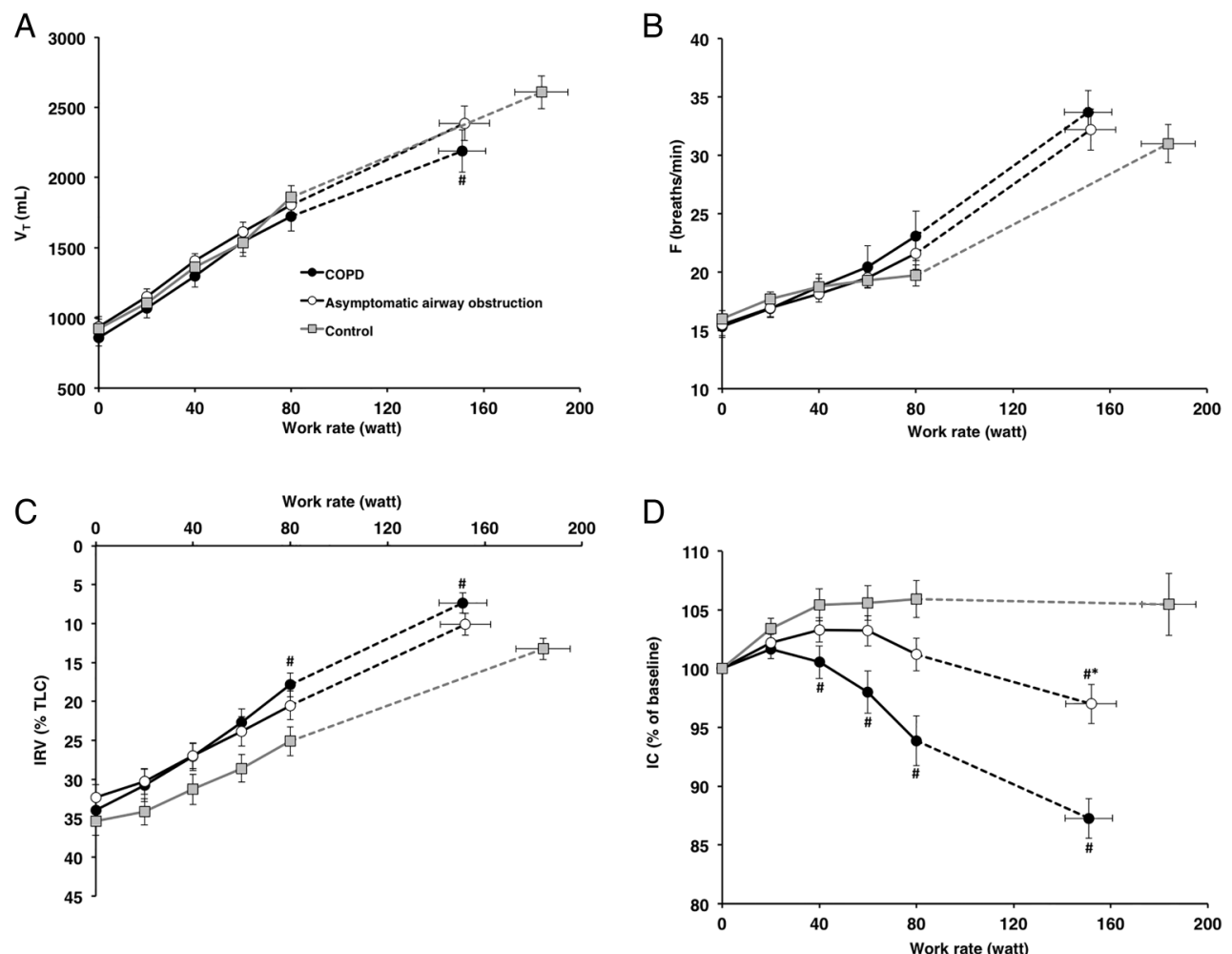

Figure 2 Tidal volume (VT; A), breathing frequency (F; B), inspiratory reserve volume (IRV, expressed as a percentage of total lung capacity (TLC), C) and inspiratory capacity (IC, expressed as a percentage of the value measured at rest during the exercise test; D) are plotted in relation to work rate. Values are means \pm SEM. ${ }^{*} p<0.05$ versus healthy controls at a standardised work rate; ${ }^{*} p<0.05$ versus patients with COPD at a standardised work rate (Scheffe's tests).

asymptomatic airway obstruction could contribute to explain differences in dyspnoea, but we are unable to demonstrate this with our data. IRV as a function of WR was slightly lower in the COPD group than in the group of asymptomatic subjects with airway obstruction. A parallel can be made between our finding and the results of previous studies showing that response to exercise does not depend solely on the magnitude of airway

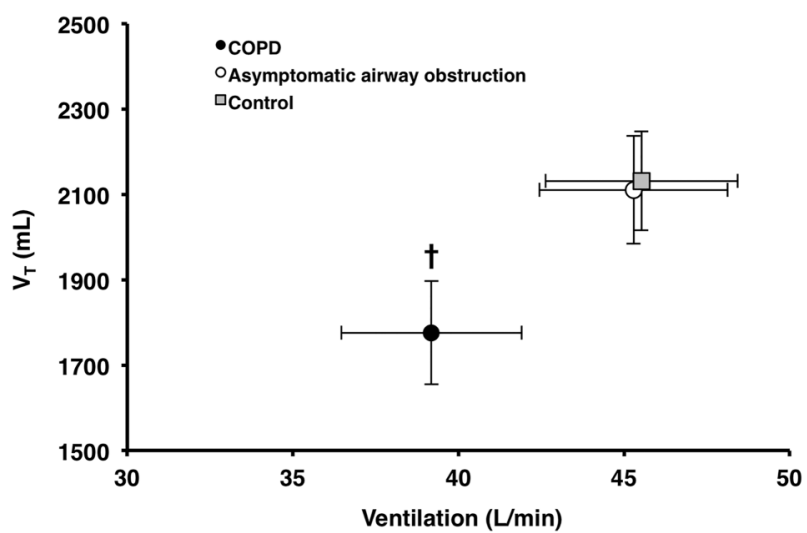

Figure 3 On evaluation of individual plots of minute ventilation $\left(V^{\prime} E\right)$ versus tidal volume (VT) (Hey plots), the group of asymptomatic subjects with airway obstruction had an inflection point of the relationship between VT and V'E at a similar VT for a similar V'E compared with controls. By contrast, the inflection point occurred at a lower VT for a lower V'E in the COPD group $(p<0.0001)$. Graphs represent mean $\pm S E$ values. ${ }^{\dagger} p<0.05$ versus healthy controls and versus asymptomatic subjects with airway obstruction. obstruction. ${ }^{35-37}$ For example, Gagnon et al demonstrated in a crossover study involving patients with moderate to severe patients with COPD that spinal anaesthesia, through inhibition of sensory afferents from the lower limbs, did not change maximal exercise capacity but improved ventilatory efficiency and exercise tolerance during endurance exercise. ${ }^{37}$ Similarly, Leith and Brown reported that the dynamic measurement of residual volume depends on the static balance between muscle and elastic recoil forces of the respiratory system, and also on the ability of subjects to perform prolonged expiration at very low expiratory flows. ${ }^{36}$

Our study population was carefully selected in order to avoid as far as possible confounders that could interfere with our results. Our three groups were carefully matched for age, sex and BMI, as these factors can impact on dyspnoea evaluation. ${ }^{38}$ We also paid attention to exclude from our study subjects with cardiac comorbidities. This is important, because an association between chronic heart failure and COPD frequently coexists, ${ }^{39}$ and dynamic hyperinflation during exercise has been reported in patients with chronic heart failure and normal spirometry. ${ }^{40}$ In our study, significant cardiac impairment was unlikely to have contributed to dyspnoea and/or to dynamic hyperinflation since heart rate responses, $\mathrm{O}_{2}$ pulse at peak exercise and blood pressure measurements were normal and similar in the three study groups.

The practical consequences of our findings for the management of subjects with airway obstruction detected by screening remain to be determined. Some physiological studies have suggested a rationale for the utility of long-acting bronchodilators in patients with mild COPD, with a view to decreasing dynamic gas trapping, improving resultant restrictive mechanical 
constraints on VT expansion and thus improving exercise capacity. ${ }^{4} 41$ Our approach provides evidence that about half of asymptomatic subjects with mild airway obstruction have significant dynamic hyperinflation. Although dynamic hyperinflation contributes to exercise limitation and dyspnoea, the benefits of inhaled bronchodilators on the reduction in exertional dyspnoea is far from warranted in these subjects with normal IC at rest. Indeed, it has been demonstrated elsewhere that patients who derive the greatest reduction in exertional dyspnoea with bronchodilator treatments are those with the most severe lung hyperinflation at baseline. ${ }^{41}$

\section{Limitations}

Among the limitations of our study, the criteria used to define asymptomatic subjects may be open to discussion. The latest American Thoracic Society statement reaffirmed that the experience of dyspnoea 'derives from interactions among multiple physiological, psychological, social, and environmental factors' ${ }^{38}$ It is acknowledged that the mMRC scale yields a unidimensional rating of disability or activity limitation, and only provides information on the domain of symptom impact and/or burden. Thus, this definition criterion in our study did not explore other domains of dyspnoea measurement, such as affective distress and sensory-perceptual experience. ${ }^{38}$ Nevertheless, we believe that the mMRC criterion was able to capture differences between symptomatic subjects, and asymptomatic subjects with airway obstruction in our study, for several reasons. First, the BDI, which was not a selection criterion, was similar in asymptomatic subjects with airway obstruction and in healthy subjects, and was more than two points lower in symptomatic COPD subjects compared with the two other groups. Second, health status measured by the SGRQ was similar in asymptomatic subjects with airway obstruction and in healthy controls, and was poorer in symptomatic COPD compared with the other two groups. Third, although we did not record any information on usual physical activity in the subjects in our study, it is unlikely that asymptomatic subjects with airway obstruction minimised dyspnoea compared with matched patients with COPD through activity avoidance because WR, $\mathrm{V}^{\prime} \mathrm{O}_{2}$, heart rate and breath frequency at ventilatory threshold were similar in these two groups (see online supplementary table S2), suggesting that deconditioning, if any, was also similar.

\section{CONCLUSIONS}

In summary, our findings suggest that subjects with mild significant airway obstruction (postbronchodilator $\mathrm{FEV}_{1} / \mathrm{FVC}<\mathrm{LLN}$ with normal $\mathrm{FEV}_{1}$ ) who do not present with symptoms of COPD do not represent a physiological variant, but have early signs of obstructive abnormalities. When they are detected by screening, these cases may, therefore, deserve closer attention and may warrant regular follow-up.

\section{Author affiliations}

${ }^{1}$ Service de Physiologie-Explorations Fonctionnelles, Besançon, France

${ }^{2}$ Service de Pneumologie, Besançon, France

${ }^{3}$ Sorbonne Universités, INSERM, UMR_S 1158, Neurophysiologie Respiratoire Expérimentale et Clinique, Paris, France

${ }^{4}$ AP-HP, Groupe Hospitalier Pitié-Salpêtrière Charles Foix, Service des Explorations Fonctionnelles de la Respiration, de l'Exercice et de la Dyspnée, Paris, France

${ }^{5}$ EA 3920, Université de Franche-Comté, Besançon, France

${ }^{6}$ Centre de Méthodologie Clinique, CHU Besançon, Besançon, France

${ }^{7}$ Epidémiologie des Maladies Respiratoires et Allergiques i-PLESP INSERM et UPMC, Paris, France

${ }^{8}$ Service de Pneumologie et Soins Intensifs Respiratoires, Groupe Hospitalier Cochin, Site Val de Grâce, AP-HP et Université Paris Descartes (EA2511), Sorbonne-ParisCité, Paris, France

${ }^{9}$ UMR CNRS Chrono Environnement, Université de Franche-Comté, Besançon, France
}

Acknowledgements The authors would like to express their appreciation for the subjects who participated in the study. The authors also thank the clinical staff who contributed to the measurements. We are indebted to Antonin Grisey, Fanny Petitcuenot, Pauline Roux and Marc Laplante for having performed most of the spirometries of the screening programme, and to Dr Didier Pernet, Dr Jean-Charles Polio and Dr Marie Gainet-Brun for having referred most of the symptomatic subjects with mild COPD. The authors thank Fiona Ecarnot (EA3920, University Hospital Besancon, France) for editorial assistance.

Contributors All authors contributed to the content and writing of the manuscript In addition: BD was the principal investigator and contributed the original idea for the study; BD, TS, PL and J-CD made substantial contributions to the conception and design of the work; TS, AG, MP and BD performed all analyses; J-CD and BD obtained study funding; all authors made substantial contributions to the acquisition or interpretation of data for the work; BD wrote the first draft of the manuscript. $B D, T S, P L, M P, M V-P, I A-M, N R$ and J-CD revised the manuscript for important intellectual content.

Competing interests None declared.

Patient consent Obtained.

Ethics approval CPP Est; P-2011-119.

Provenance and peer review Not commissioned; externally peer reviewed.

\section{REFERENCES}

1 Vestbo J, Hurd SS, Agustí AG, et al. Global strategy for the diagnosis, management and prevention of chronic obstructive pulmonary disease: GOLD executive summary. Am J Respir Crit Care Med 2013;187:347-65.

2 Halbert RJ, Natoli JL, Gano A, et al. Global burden of COPD: systematic review and meta-analysis. Eur Respir J 2006;28:523-32.

3 Soriano JB, Zielinski J, Price D. Screening for and early detection of chronic obstructive pulmonary disease. Lancet 2009;374:721-32.

4 Ofir D, Laveneziana P, Webb KA, et al. Mechanisms of dyspnea during cycle exercise in symptomatic patients with GOLD stage I chronic obstructive pulmonary disease. Am J Respir Crit Care Med 2008:177:622-9.

5 Guenette JA, Chin RC, Cheng S, et al. Mechanisms of exercise intolerance in Global Initiative for Chronic Obstructive Lung Disease grade 1 COPD. Eur Respir J 2014;44:1177-87

6 Díaz AA, Morales A, Díaz JC, et al. CT and physiologic determinants of dyspnea and exercise capacity during the six-minute walk test in mild COPD. Respir Med 2013;107:570-9.

7 Elbehairy AF, Webb KA, Neder JA, et al. Should mild COPD be treated? Evidence for early pharmacological intervention. Drugs 2013;73:1991-2001.

8 van den Boom G, van Schayck CP, van Möllen MP, et al. Active detection of chronic obstructive pulmonary disease and asthma in the general population. Results and economic consequences of the DIMCA program. Am J Respir Crit Care Med 1998;158:1730-8.

9 Buffels J, Degryse J, Heyrman J, et al. Office spirometry significantly improves early detection of COPD in general practice: the DIDASCO Study. Chest 2004;125:1394-9.

10 Bednarek M, Maciejewski J, Wozniak M, et al. Prevalence, severity, and underdiagnosis of COPD in primary care setting. Thorax 2008;63:402-7.

11 Zieliñski J, Bednarek M. Early detection of COPD in a high-risk population using spirometric screening. Chest 2001;119:731-6.

12 Bridevaux PO, Gerbase MW, Probst-Hensch NM, et al. Long-term decline in lung function, utilisation of care and quality of life in modified GOLD stage 1 COPD Thorax 2008:63:768-74.

13 Bertens LC, Reitsma JB, van Mourik Y, et al. COPD detected with screening: impact on patient management and prognosis. Eur Respir J 2014;44:1571-8.

14 de Marco R, Accordini S, Antò JM, et al. Long-term outcomes in mild/moderate chronic obstructive pulmonary disease in the European community respiratory health survey. Am J Respir Crit Care Med 2009;180:956-63.

15 Mannino DM, Sonia Buist A, Vollmer WM. Chronic obstructive pulmonary disease in the older adult: what defines abnormal lung function? Thorax 2007:62:237-41.

16 Vaz Fragoso CA, Concato J, McAvay G, et al. Defining chronic obstructive pulmonary disease in older persons. Respir Med 2009;103:1468-76.

17 Quanjer PH, Cooper B, Ruppel GL, et al. Defining airflow obstruction. Eur Respir 2015;45:561-2.

18 Degano B, Bouhaddi M, Laplante JJ, et al. [COPD in dairy farmers: screening, characterization and constitution of a cohort. The BALISTIC study]. Rev Mal Respir 2012;29:1149-56

19 Guillien A, Puyraveau M, Soumagne T, et al. Prevalence and risk factors for COPD in farmers: a cross-sectional controlled study. Eur Respir J 2016;47:95-103.

20 Quanjer PH, Stanojevic S, Cole TJ, et al. Multi-ethnic reference values for spirometry for the 3-95-yr age range: the global lung function 2012 equations. Eur Respir J 2012;40:1324-43. 
21 Macintyre N, Crapo RO, Viegi G, et al. Standardisation of the single-breath determination of carbon monoxide uptake in the lung. Eur Respir $J$ 2005;26:720-35.

22 Wanger J, Clausen JL, Coates $A$, et al. Standardisation of the measurement of lung volumes. Eur Respir J 2005;26:511-22.

23 Palange $\mathrm{P}$, Ward SA, Carlsen $\mathrm{KH}$, et al. Recommendations on the use of exercise testing in clinical practice. Eur Respir J 2007;29:185-209.

24 Jones NL, Makrides L, Hitchcock C, et al. Normal standards for an incremental progressive cycle ergometer test. Am Rev Respir Dis 1985;131:700-8.

25 Borg GA. Psychophysical bases of perceived exertion. Med Sci Sports Exerc 1982;14:377-81.

26 O'Donnell DE, Revill SM, Webb KA. Dynamic hyperinflation and exercise intolerance in chronic obstructive pulmonary disease. Am J Respir Crit Care Med 2001;164:770-7.

27 Laveneziana P, Webb KA, Ora J, et al. Evolution of dyspnea during exercise in chronic obstructive pulmonary disease: impact of critical volume constraints. Am J Respir Crit Care Med 2011;184:1367-73.

28 Hey EN, Lloyd BB, Cunningham DJ, et al. Effects of various respiratory stimuli on the depth and frequency of breathing in man. Respir Physiol 1966;1:193-205.

29 Elbehairy AF, Raghavan N, Cheng S, et al. Physiologic characterization of the chronic bronchitis phenotype in GOLD grade IB COPD. Chest 2015;147: 1235-45.

30 Lamprecht B, Soriano JB, Studnicka M, et al. Determinants of underdiagnosis of COPD in national and international surveys. Chest 2015;148:971-85.

31 Lyngsø AM, Gottlieb V, Backer V, et al. Early detection of COPD in primary care: the Copenhagen COPD screening project. COPD 2013;10:208-15.
32 Zachariades AG, Zachariadou T, Adamide T, et al. Prevalence of chronic obstructive pulmonary disease in Cyprus: a population-based study. COPD 2012;9:259-67.

33 Roche N, Dalmay F, Perez T, et al. Impact of chronic airflow obstruction in a working population. Eur Respir J 2008;31:1227-33.

34 Barjaktarevic I, Springmeyer S, Gonzalez X, et al. Diffusing capacity for carbon monoxide correlates best with tissue volume from quantitative CT scanning analysis. Chest 2015;147:1485-93.

35 Neder JA, Arbex FF, Alencar MC, et al. Exercise ventilatory inefficiency in mild to end-stage COPD. Eur Respir J 2015;45:377-87.

36 Leith DE, Brown R. Human lung volumes and the mechanisms that set them. Eur Respir J 1999;13:468-72.

37 Gagnon P, Bussières JS, Ribeiro F, et al. Influences of spinal anesthesia on exercise tolerance in patients with chronic obstructive pulmonary disease. Am J Respir Crit Care Med 2012;186:606-15.

38 Parshall MB, Schwartzstein RM, Adams L, et al. An official American Thoracic Society statement: update on the mechanisms, assessment, and management of dyspnea. Am J Respir Crit Care Med 2012;185:435-52.

39 Tavazzi L, Swedberg K, Komajda M, et al. Clinical profiles and outcomes in patients with chronic heart failure and chronic obstructive pulmonary disease: an efficacy and safety analysis of SHIFT study. Int J Cardiol 2013;170:182-8.

40 Chiari S, Torregiani C, Boni E, et al. Dynamic pulmonary hyperinflation occurs without expiratory flow limitation in chronic heart failure during exercise. Respir Physiol Neurobiol 2013;189:34-41.

41 O'Donnell DE, Laveneziana P, Ora J, et al. Evaluation of acute bronchodilator reversibility in patients with symptoms of GOLD stage I COPD. Thorax 2009;64:216-23. 